\title{
Destek Personellerinin İletişim Becerileri ve Empati Düzeylerinin Belirlenmesi: Kamu Hastanelerinde Bir Uygulama
}

DOI: $10.26466 /$ opus.561414

\author{
Şirin Özkan* - Gökhan Aba** -Yusuf Çelik*** \\ * Dr. Öğr. Üyesi, Bandırma Onyedi Eylül Üni., Sağlık Bilimleri Fak., Bandırma / Balıkesir / Türkiye \\ E-Posta: sozkan@bandirma.edu.tr \\ ORCID: 0000-0001-9153-6481 \\ **Dr. Öğr. Üyesi, Bandırma Onyedi Eylül Üni., Sağlık Bilimleri Fak., Bandırma / Balıkesir / Türkiye \\ E-Posta: gokhanaba20@hotmail.com \\ ORCID: $0000-0002-4742-3217$ \\ *** Prof. Dr., Hacettepe Üniversitesi, İktisadi ve İdari Bilimler Fakültesi, Ankara / Türkiye \\ E-Posta: yucelik@hacettepe.edu.tr \\ ORCID: $\underline{0000-0002-8051-9245}$
}

\section{Öz}

Sağglk hizmeti sunucularının empati davranışlar ile iletişim becerilerinin yüksek olması daha iyi sağlık sonuçlarına, kaliteli bakıma, hastanın tedaviye daha etkin katılımına ve yüksek hasta memnuniyetine ulaşılması açısından önemlidir. Bu çalışmanın amacı, kamu hastanelerinde çalışan hasta kayıt ve karşılama personeli, hastane servisleri temizlik personeli ile hasta destek ve taşıma personellerinin iletişim becerileri ve empati eğilim düzeylerinin belirlenmesi ve aralarındaki ilişkinin ortaya konmasıdır. Tanımlayıcı tipteki bu araştırma, Ocak-Haziran 2015 tarihleri arasında, Kocaeli'deki tüm kamu hastanelerinde (dokuz hastane) yürütülmüştür. Araştırmaya hastanelerde çalışan 387 destek personeli (hasta kayıt ve karşılama personeli, hastane servisleri temizlik personeli, hasta destek ve taşıma personelleri) katılmıştır. İletişim Becerileri ve Empati Ĕ̆̈ilim Ölçekleri kullanılmıştır. Araştırma bulgularına göre; destek personelin iletişim beceri ve empati eğilim düzeylerinin orta düzeyde olduğu, kadınların erkeklere göre daha yüksek iletişim becerileri (zihinsel ve davranışsal) ve empati eğilim düzeyine sahip olduğu, toplam hizmet süresi ile duygusal, davranışsal ve genel iletişim becerileri arasında istatistiksel açıdan anlamlı ilişki olduğu bulunmuştur. Ayrıca iletişim becerileri alt boyutlar ile empati eğilim düzeyleri arasında pozitif yönde istatistiksel olarak anlamlı bir ilişki olduğu belirlenmiştir. Sonuç olarak, destek personellerinin iletişim becerileri ve empati düzeylerinin arttırlmasına yönelik, etkili ve sürekli hizmet içi eğitimlerin düzenlenmesi gerektiği düşünülmektedir.

Anahtar Kelimeler: İletişim, Empati, Destek Personeli 


\title{
Determination of Communication Skills and Empathy Levels of Support Staff: An Application in The Public Hospitals
}

\begin{abstract}
In The high level communication skills and empathy behaviors of the healthcare professionals is important to achieve better health outcomes, provide high quality of health care, effective patient participation to the treatment and higher patient satisfaction. The aim of this study is to determine levels and relationship between communication skills and empathy tendency of support staff in public hospitals. A descriptive study was conducted between January and June 2015 in all public hospitals (nine hospitals) in Kocaeli. 387 support staff working in public hospitals (receptionist, clinical assistants, patient services assistants and porters) involved to the study. Communication Skills and Empathy Tendency Scales were used in the study. This study indicated that the level of communication skills and empathy tendency of support staff is in medium level, women have higher communication skills (mental and behavioral) and empathy tendency than men. Also it was found that there was a significant relationship between total working experience and emotional, behavioral and general communication skills. In addition, there was significant relationship between sub-dimensions of communication skills and empathy tendency levels. As a result, effective and continuous in-service trainings should be organized to improve communication skills and empathy levels of support staff.
\end{abstract}

Keywords: Communication, Empathy, Support Staff 


\section{Giriş}

Sağlık hizmetinin etkili bir şekilde sunulabilmesi, sağlık ekibi üyelerinin sahip olduğu iletişim becerileriyle doğru orantılıdır. Sağlık bakım sitemindeki tüm çalışanlar sağlıklı/hasta bireylerle doğrudan yüz yüze ilişki kurmak durumunda olduğundan, iletişim becerileri güçlü olmalıdır (Şahin ve Kardaş Özdemir, 2015, s.1; Akgün ve Çetin, 2018, s.104). Karşılıklı güven çerçevesinde, hizmet verilen bireyi tanılamak ve sorunları ile daha etkin baş edebilir, ihtiyaçlarını karşılayabilmek için iletişim oldukça önem arz etmektedir (Özdemir, 2011, s.9).

Hastalar iletişime, bilgilendirmenin anlaşılır olmasına ve kendi deneyimlerinin dikkate alınmasına önem vermektedirler (Nørgaard vd., 2012: 699). İletişimdeki aksaklıklar; hastanın memnuniyetini, tedaviye uyum sağlamasını, yapılan sağlık harcamalarını ve sağlıkla ilgili diğer çıktıları olumsuz etkilediğinden, sağlık bakım hizmetlerinde iletişim becerilerinin etkinliği oldukça önem arz etmektedir (Tiryaki Şen vd., 2013, s.14).

İletişim, en genel tanımıyla, bir kişinin bir bilgiyi anlaşılır biçimde başka kişilere aktarılmasıdır. Başka bir ifadeyle, gönderici ve alıcı arasında anlamları ortak kılmaya yönelik bir çabadır (Bahar, 2016, s.2). Sağlık iletişimi ise, sağlıkla ilgili bakım sürecine dâhil olan profesyonel hizmet sunucuları ve hastalar arasında bilgi, görüş ve duyguların iletilmesini içermektedir (Okay, 2016, s.11). Etkili sağlık bakımı sunumu için sağlık ekibi üyeleri ile hasta arasında karşılıklı güvene dayalı bir iletişim ve etkileşim kurulması, bireyin bir bütün olarak tanımlanması, bakım gereksinimlerinin belirlenmesi ve bireyin sorunları ile etkin baş edebilmesi konusunda yardım edilmesi gerekmektedir (Şahin ve Kardaş Özdemir, 2015, s.1).

Empati ise, yardım ilişkisinin temel bileşenlerinden biridir. Empati; bireyin kendisini karşısındakinin yerine koyarak onun bakış açısı ile olaylara bakması, o kişinin duygularını ve düşüncelerini doğru olarak anlaması, hissetmesi ve bu durumu ona iletmesi sürecidir (Pazar vd., 2017, s.368). Sağlık çalışanlarının empati davranışları ile hastalara kaliteli bakım sağlanmasında, hastanın tedaviye daha etkin katılması, daha yüksek hasta memnuniyeti ve bağlılığına ve daha iyi sağlık sonuçları ile ilişkili olduğu belirlenmiştir (Lamothe vd., 2015, s.26; Lin vd., 2012, s.1). Ayrıca, 
empati sağlık profesyonellerinin kendilerini daha iyi hisseme, daha az tükenme, daha yüksek klinik yeterlilik ve daha az tıbbi risk alma ile ilişkili olduğu belirlenmiştir. Hatta sağlık profesyonelinin empati düzeylerinin sağlı bakım maliyetlerini azalttığı hasta odaklı iletişimin ise tanı koymaya yönelik yapılan test maliyetlerini azalttığı belirlenmiştir (Kelm vd., 2014, s.2) Empatinin mümkün olduğu durumlarda kişi, başka bir insanın duygularına duygusal bir tepki verebilir ve kendisiyle diğerleri arasında bir ayrım yapabilir. Eğer sağlık çalışanlarının duygularını düzenlemekte zorluk çekerlerse, zamanla duygusal olarak tükenebilirler (Lamothe vd., 2015, s.20).

Hastalık ve hastaneye yatış hasta birey ve yakınları için önemli deneyimlerdendir (Şahin ve Kardaş Özdemir, 2015, s.2). Hastanelere başvuran hasta ve yakınlarının genelde sıkıntı, endişe, gerginlik, huzursuzluk veya korku duygularıyla stres içinde olmaları nedeniyle sağlıklı iletişim kurmaları her zaman mümkün olamamaktadır (Bekcan, 2015, s.48). Sağlık hizmetleri sunumun her aşamasında görev alan tüm çalışanların, hastaya sürekli etkin bakım verebilmesi, hasta yakınlarına gerekli desteği sağlayabilmesi ve kendi ruh sağlığını koruyabilmesi beklenmektedir. Bunun için de sağlık hizmetlerindeki tüm çalışanların etkin iletişim ve empati becerisine ara ara değerlendirilmesi, profesyonel iletişim becerileri ve empatik becerilerinin tekrarlayan eğitimlerle desteklenmesi gerekmektedir.

Hastalar hastanelere geldiklerinde profesyonel sağlık çalışanlarından önce destek personel tarafından karşılanmakta ve hastanede oldukları süre boyunca sağlık çalışanları kadar destek personeli ile de iletişimi devam etmektedir. Literatürde yer alan çalışmalar, genellikle sağlık çalışanlarına yönelik gerçekleştirilmiştir (Tiryaki Şen vd., 2013; Şahin ve Kardaş Özdemir, 2015; Bauchat vd., 2016; Wilkinson vd., 2017; Moore vd., 2018). Araştırmada sağlık çalışanları dışındaki destek personelin iletişim becerileri ve empatik eğilim düzeylerini değerlendirilmesi hedeflenmiştir.

$\mathrm{Bu}$ araştırmanın amacl; Kocaeli'nde yer alan kamu hastanelerinde çalışan hasta kayıt ve karşılama personeli, hastane servisleri temizlik personeli ile hasta destek ve taşıma personellerinin iletişim becerileri ve empati eğilim düzeylerini belirlemek ve aralarındaki ilişkiyi ortaya koymaktır. Bu amaçla aşağıda sıralanan soruların cevapları belirlenmeye çalışılmıştır; 
- Destek personelin iletişim beceri ve empati eğilim düzeyleri ile sosyodemografik özellikleri arasında istatistiksel açıdan anlamlı bir ilişki var midır?

- Destek personelin iletişim beceri ve empati eğilim düzeyleri nasıldır?

- Destek personelin iletişim beceri ve empati eğilim düzeyleri arasında istatistiksel olarak anlamlı bir ilişki var mıdır?

\section{Yöntem}

Tanımlayıcı tipteki bu araştırma, Ocak-Haziran 2015 tarihleri arasında, Kocaeli'deki tüm kamu hastanelerinde (dokuz hastane) yürütülmüştür. Araştırma evrenini, bu hastanelerde çalışan 867 destek personelin (hasta kayıt ve karşlama personel, hastane servisleri temizlik personeli, hasta destek ve taşıma personelleri) oluşturmuştur. Araştırmada örneklem seçimine gidilmemiş, hastanelerde çalışan tüm destek personeli çalışmaya dâhil edilmek istenmiştir. Verilerin toplandığ 1 tarihlerde, hastanede bulunan 426 kişi çalışmaya katılmayı kabul etmiştir. Yapılan ön analizlerde, verileri, araştırma için kullanılabilir nitelikte olan 387 kişi araştırmanın örneklemini oluşturmuştur.

Araştırma için, Kocaeli Kamu Hastaneler Birliği Genel Sekreterliğinden gerekli kurumsal izinler alınmıştır. Veri toplama tekniği olarak online anket uygulaması gerçekleştirilmiştir. Kurumdan e-mail adresleri alınan 867 destek personeline anketler gönderilmiş, 426 personelden geri dönüş sağlanmıştır. Kullanılan ankette, katılımcıların sosyodemografik özelliklerine yönelik sorular ve iletişim beceri ve empati eğilim düzeylerini ölçmeye yönelik ifadeler yer almaktadır.

İletişim Becerileri Ölçeği: Ersanlı ve Balcı (1998) tarafından geliştirilen ölçeğin geçerlik ve güvenirlik çalışmalarında güvenirliği ölçmek için yapılan test tekrar test sonucunda $\mathrm{r}=0,68$ ve test yarılama analizinde ise $\mathrm{r}=0,64$ bulunmuştur. Ölçeğin iç tutarlılığını belirlemek amacıyla hesaplanan Cronbach Alpha katsayısı 0,72'dir. Ölçeğin geçerlik çalışmasıyla ilgili olarak paralel form uygulaması yapılmış, korelasyon katsayısı r= 0.70 olarak bulunmuştur. 45 maddeden oluşan ölçek, zihinsel, duygusal ve davranışsal iletişim becerileri olmak üzere üç boyuttan oluşmaktadır. Her bir boyutu ölçen 15 madde vardır. 1=Hiçbir zaman, 5= 
Her zaman olmak üzere 5'li likert tipinde hazırlanmıştır. Ölçeğin genelinden alınabilecek en yüksek puan 225, en düşük puan ise 45 'tir. Ölçeğin her bir alt boyutundan en yüksek puan 75, en düşük 15 puan alınabilmektedir. Puanın yüksek olması, bireyin iletişim becerisinin de yüksek olduğunu göstermektedir. $\mathrm{Bu}$ çalışmada, ölçeğin güvenirlik analizi sonucunda Cronbach Alpha değeri 0,870 olarak bulunmuştur. Zihinsel, duygusal ve davranışsal boyutların Cronbach Alpha değerleri ise sırasıyla 0,676; 0,690 ve $0,728^{\prime}$ dir.

Empatik Ĕ̆ilim Ölçeği: Bireylerin günlük yaşamında empati kurma eğilimlerini ölçmeyi amaçlayan ölçek, Dökmen (1988) tarafından geliştirilmiştir. Ölçek, likert tipinde (1=Tamamen aykırı, 5=Tamamen uygun) hazırlanmış 20 maddeden oluşmaktadır. Testten alınabilecek en düşük puan; $1 \times 20=20$; en yüksek puan ise 5×20=100'dür. Puanın yüksek olması, empati eğilimin yüksek olduğunu, düşük olması ise empati eğilimin düşük olduğunu göstermektedir. Ölçekte yer alan negatif ifadeler tersten puanlanmaktadır. Ölçeğin Cronbach Alpha değeri 0,812'tir.

Verilerin değerlendirilmesinde, SPSS 21.0 programından faydalanılmıştır. Verilerin analizi için tanımlayıcı istatistikler, t-Test, Anova ve Pearson Korelasyon analizleri kullanılmıştır. Post Hoc yöntemi olarak Schefee testi kullanılmıştır. Normal dağılıma uymayan değişkenlerin analizinde non-parametrik analizler (Kruskal-Wallis) kullanılmıştır. Anlamlılık düzeyi $\mathrm{p}<0,05$ olarak alınmıştır.

Araştırma, sadece Kocaeli ilindeki kamu hastanelerinde çalışan destek personelin, araştırmanın yapıldığ dönem içerisinde vermiş oldukları cevaplarla sınırlıdır. Dolayısıyla, sonuçlar diğer illerdeki hastaneleri, özel hastaneleri ve tüm sağlık çalışanlarını genelleyemez.

\section{Bulgular}

Destek personelin sosyodemografik özellikleri incelendiğinde, katılımcların \% 87,9'unun kadınlardan oluştuğu, \% 43,4'ünün 30-39 yaş

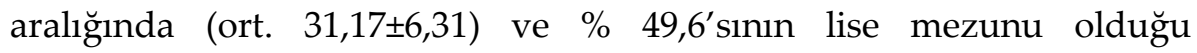
saptanmıştır. \% 61,5'inin evli, \% 92,5'sinin 500-1500 TL arasında gelire sahip olduğu ve 6-10 yıl hizmet süreleri bulunanların oranının \% 46,8 
olduğu belirlenmiştir. Çalışmada ayrıca, iletişim becerilerine yönelik sorular yöneltilmiştir. Buna göre, destek personelin \%72,1'i iletişim ile ilgili çalıştıkları hastanelerde hizmet içi eğitim aldıkları, \% 41,6'sı, aldıkları eğitimin iyi seviyede etkili olduğunu bildirmişlerdir. Katılımcıların büyük çoğunluğu (\% 92) kendilerinin iletişim beceri düzeylerinin yüksek olduğunu düşünmektedirler.

Destek personelin iletişim becerileri ile empati eğilim düzeyleri ölçek puan ortalamalarının dağılımı incelendiğinde; iletişim beceri ve empati eğilim düzeylerinin orta düzeyde olduğu görülmüştür (Tablo 1).

Araştırmaya katılan destek personelin sosyodemografik özelliklerine göre iletişim ve empati beceri düzeyleri incelendiğinde; kadınların erkeklere göre zihinsel ve davranışsal boyutlar açısından daha yüksek iletişim becerileri ve empati eğilim düzeyine sahip olduğu, toplam hizmet süresi ile duygusal, davranışsal ve genel iletişim becerileri arasında istatistiksel açıdan anlamlı fark olduğu bulunmuştur $(\mathrm{p}<0,05)$. Yapılan Post Hoc analizi (Schefee Testi) sonucunda, hizmet süresi 6-10 yıl arasında olanların 2-5 yıl arasında olanlara göre, duygusal, davranışsal beceri boyutlarında ve toplamda daha yüksek iletişim becerilerine sahip olduğu belirlenmiştir (Tablo 2). Katılımcıların diğer sosyodemografik özellikleri ile iletişim ve empati düzeyleri arasında istatistiksel açıdan anlamlı bir fark saptanmamıştır.

Tablo 1. İletişim Becerileri ve Empati Ĕ̆ilim Ölçek Puan Ortalamalarının Dağılımı

\begin{tabular}{llll}
\hline & $\mathbf{X} \pm$ SS & Min. & Max. \\
\hline Zihinsel Beceri & $62,69 \pm 5,03$ & 46 & 74 \\
\hline Duygusal Beceri & $58,78 \pm 6,07$ & 39 & 74 \\
\hline Davranıșsal Beceri & $65,54 \pm 5,56$ & 45 & 75 \\
\hline $\begin{array}{l}\text { İletişim Becerileri } \\
\text { (Toplam) }\end{array}$ & $187,02 \pm 14,31$ & 140 & 220 \\
\hline Empatik Eğilim & $76,71 \pm 8,94$ & 51 & 99 \\
\hline
\end{tabular}


Tablo 2. Destek Personelin Sosyodemografik Özelliklerine Göre İletişim ve Empati Düzeyleri Puan Ortalamalarının Karşılaştırılması

\begin{tabular}{|c|c|c|c|c|c|c|c|}
\hline \multirow[b]{2}{*}{ Değişkenler } & \multirow[b]{2}{*}{$\mathbf{n}$} & \multirow[b]{2}{*}{$\%$} & \multicolumn{4}{|c|}{ İletişim Becerileri } & \multirow[b]{2}{*}{$\begin{array}{l}\text { Empati } \\
\text { Eğilim } \\
X \pm S S\end{array}$} \\
\hline & & & $\begin{array}{l}\text { Zihinsel } \\
\mathrm{X} \pm \mathrm{SS}\end{array}$ & $\begin{array}{l}\text { Duygusal } \\
\mathrm{X} \pm \mathrm{SS}\end{array}$ & $\begin{array}{l}\text { Dav- } \\
\text { ranışsal } \\
X \pm S S\end{array}$ & $\begin{array}{l}\text { Toplam } \\
X \pm S S\end{array}$ & \\
\hline \multicolumn{8}{|l|}{ Yaş } \\
\hline 29 yaş ve altı & 168 & 43,4 & $52,7 \pm 4,5$ & $50,1 \pm 5,7$ & $60,9 \pm 5,7$ & $163,7 \pm 14,3$ & $76,4 \pm 9,2$ \\
\hline 30-39 yaş & 174 & 45,0 & $53,4 \pm 4,5$ & $51,1 \pm 5,0$ & $62,2 \pm 5,2$ & $166,6 \pm 12,8$ & $76,6 \pm 9,1$ \\
\hline \multirow[t]{2}{*}{40 yaş ve üzeri } & 45 & 11,6 & $54,0 \pm 3,7$ & $51,8 \pm 3,9$ & $62,0 \pm 4,7$ & $167,8 \pm 10,3$ & $78,8 \pm 7,4$ \\
\hline & & & $\begin{array}{l}F: 1,773 \\
p>0,05\end{array}$ & $\begin{array}{l}F: 2,834 \\
p>0,05\end{array}$ & $\begin{array}{l}F: 2.336 \\
p>0,05\end{array}$ & $\begin{array}{l}F: 2,833 \\
p>0,05\end{array}$ & $\begin{array}{l}F: 1,350 \\
p>0,05\end{array}$ \\
\hline \multicolumn{8}{|l|}{ Cinsiyet } \\
\hline Erkek & 47 & 12,1 & $51,6 \pm 4,6$ & $51,1 \pm 5,0$ & $60,0 \pm 6,2$ & $162,7 \pm 13,0$ & $74,0 \pm 10,2$ \\
\hline \multirow[t]{2}{*}{ Kadın } & 340 & 87,9 & $53,3 \pm 4,5$ & $50,7 \pm 5,3$ & $61,8 \pm 5,2$ & $165,8 \pm 13,4$ & $77,1 \pm 8,8$ \\
\hline & & & $\begin{array}{l}\mathrm{t}:-2,324 \\
\mathrm{p}<0,05\end{array}$ & $\begin{array}{l}\mathrm{t}: 0,510 \\
\mathrm{p}>0,05\end{array}$ & $\begin{array}{l}\mathrm{t}:-2,145 \\
\mathrm{p}<0,05\end{array}$ & $\begin{array}{l}\mathrm{t}:-1,440 \\
\mathrm{p}>0,05\end{array}$ & $\begin{array}{l}\mathrm{t}:-2,125 \\
\mathrm{p}<0,05\end{array}$ \\
\hline \multicolumn{8}{|l|}{$\begin{array}{l}\text { Medeni } \\
\text { Durum }\end{array}$} \\
\hline Evli & 238 & 61,5 & $53,1 \pm 4,5$ & $50,6 \pm 5,5$ & $61,5 \pm 5,2$ & $165,2 \pm 13,6$ & $77,2 \pm 9,1$ \\
\hline \multirow[t]{2}{*}{ Bekâr } & 149 & 38,5 & $53,2 \pm 4,4$ & $50,9 \pm 4,7$ & $61,8 \pm 5,6$ & $165,9 \pm 12,8$ & $76,0 \pm 8,6$ \\
\hline & & & $\begin{array}{l}\mathrm{t}:-0,270 \\
\mathrm{p}>0,05\end{array}$ & $\begin{array}{l}t:-0,561 \\
p>0,05\end{array}$ & $\begin{array}{l}\mathrm{t}:-0,458 \\
\mathrm{p}>0,05\end{array}$ & $\begin{array}{l}t:-0,497 \\
p>0,05\end{array}$ & $\begin{array}{l}\mathrm{t}: 1,300 \\
\mathrm{p}>0,05\end{array}$ \\
\hline \multicolumn{8}{|l|}{ Öğrenim } \\
\hline Lise & 193 & 49,8 & $53,5 \pm 4,4$ & $50,5 \pm 5,2$ & $61,7 \pm 5,3$ & $165,8 \pm 13,2$ & $76,5 \pm 8,1$ \\
\hline Önlisans & 112 & 29,9 & $53,0 \pm 4,0$ & $51,0 \pm 4,9$ & $61,4 \pm 5,4$ & $165,3 \pm 12,7$ & $76,9 \pm 9,2$ \\
\hline \multirow[t]{2}{*}{$\begin{array}{ll}\text { Lisans } & \text { ve } \\
\text { Lisansüstü } & \\
\end{array}$} & 82 & 20,3 & $51,8 \pm 4,9$ & $48,3 \pm 5,2$ & $61,1 \pm 5,9$ & $160,7 \pm 11,7$ & $77,1 \pm 8,5$ \\
\hline & & & $\begin{array}{l}F: 1,387 \\
p>0,05\end{array}$ & $\begin{array}{l}F: 0,536 \\
p>0,05\end{array}$ & $\begin{array}{l}F: 0,741 \\
p>0,05\end{array}$ & $\begin{array}{l}F: 0,089 \\
p>0,05\end{array}$ & $\begin{array}{l}F: 0,542 \\
p>0,05\end{array}$ \\
\hline \multicolumn{8}{|l|}{ Gelir Düzeyi* $^{*}$} \\
\hline $500-1500 \mathrm{TL}$ & 358 & 92,5 & $53,1 \pm 4,5$ & $50,8 \pm 5,2$ & $61,8 \pm 5,4$ & $165,7 \pm 13,5$ & $76,9 \pm 8,8$ \\
\hline $1500-2500 \mathrm{TL}$ & 19 & 4,9 & $53,8 \pm 3,2$ & $48,6 \pm 4,2$ & $59,4 \pm 4,0$ & $161,8 \pm 9,5$ & $74,0 \pm 9,0$ \\
\hline \multirow[t]{2}{*}{$\begin{array}{l}2500 \mathrm{TL} \\
\text { ve üstü }\end{array}$} & 10 & 2,6 & $51,8 \pm 4,7$ & $51,2 \pm 5,9$ & $59,3 \pm 3,8$ & $162,3 \pm 12,1$ & $78,6 \pm 12,4$ \\
\hline & & & $\begin{array}{l}x^{2}: 1,150 \\
p>0,05\end{array}$ & $\begin{array}{l}x^{2}: 7,832 \\
p>0,05\end{array}$ & $\begin{array}{l}x^{2}: 7,351 \\
p>0,05\end{array}$ & $\begin{array}{l}x^{2}: 3,450 \\
p>0,05\end{array}$ & $\begin{array}{l}x^{2}: 1,961 \\
p>0,05\end{array}$ \\
\hline \multicolumn{8}{|l|}{ Hizmet Süresi } \\
\hline 1 yıldan az & 59 & 15,3 & $53,9 \pm 3,9$ & $51,6 \pm 4,9$ & $62,0 \pm 4,6$ & $167,5 \pm 11,6$ & $76,9 \pm 9,4$ \\
\hline $2-5$ yil & 103 & 26,6 & $52,4 \pm 4,9$ & $49,4 \pm 5,9$ & $60,6 \pm 6,1$ & $162,4 \pm 15,3$ & $75,9 \pm 10,1$ \\
\hline 6-10 yıl & 184 & 47,5 & $53,4 \pm 4,3$ & $51,3 \pm 4,9$ & $62,3 \pm 5,1$ & $167,0 \pm 12,5$ & $77,2 \pm 8,4$ \\
\hline \multirow[t]{2}{*}{11 yıl ve üzeri } & 41 & 10,6 & $53,0 \pm 4,7$ & $50,9 \pm 4,5$ & $60,6 \pm 5,0$ & $164,4 \pm 11,8$ & $77,0 \pm 7,8$ \\
\hline & & & $\begin{array}{l}F: 1,670 \\
p>0,05\end{array}$ & $\begin{array}{l}F: 3,314 \\
p<0,05\end{array}$ & $\begin{array}{l}F: 2,960 \\
p<0,05\end{array}$ & $\begin{array}{l}F: 3,159 \\
p<0,05\end{array}$ & $\begin{array}{l}F: 0,476 \\
p>0,05\end{array}$ \\
\hline \multicolumn{3}{|c|}{ Anlamlı Fark (Scheffe Testi) } & & $\begin{array}{l}2-5 \text { yil } \\
6-10 \text { yıl }\end{array}$ & $\begin{array}{l}2-5 \text { yıl } \\
6-10 \text { yıl }\end{array}$ & $\begin{array}{l}2-5 \text { yıl } \\
6-10 \text { yıl }\end{array}$ & \\
\hline
\end{tabular}

*Gelir düzeyinin normal dağılım göstermediği belirlendiğinden Kruskal-Wallis testi kullanılmıştır. 
Destek personelin iletişim becerileri ile empati eğilim ölçek puan ortalamaları karşılaştırıldığında, iletişim becerileri ve alt boyutları ile empati eğilim arasında pozitif yönde istatistiksel olarak anlamlı bir ilişki olduğu belirlenmiştir. (Tablo 3).

Tablo 3. İletişim Becerileri ve Empati Eğilim Ölçek Puan Ortalamalarn Arasındaki İlişki

\begin{tabular}{llllll}
\hline & $\begin{array}{l}\text { Zihinsel } \\
\text { Beceri }\end{array}$ & $\begin{array}{l}\text { Duygusal } \\
\text { Beceri }\end{array}$ & $\begin{array}{l}\text { Davranışsal } \\
\text { Beceri }\end{array}$ & $\begin{array}{l}\text { Iletişim } \\
\text { Beceri } \\
\text { (Toplam) }\end{array}$ & $\begin{array}{l}\text { Empatik } \\
\text { Eğilim }\end{array}$ \\
\hline Zihinsel Beceri & 1 & & & & \\
\hline Duygusal Beceri &, $644^{*}$ & 1 & & & \\
\hline Davranişsal Beceri &, $693^{*}$ &, $664^{*}$ & 1 & & \\
\hline $\begin{array}{l}\text { Iletişim Becerileri } \\
\text { (Toplam) }\end{array}$ &, $870^{*}$ &, $878^{*}$ &, $897^{*}$ & 1 & \\
\hline Empatik Eğilim &, $497^{*}$ &, $673^{*}$ &, $531^{*}$ &, $646^{*}$ & 1 \\
\hline$* 00,01$ & & & & &
\end{tabular}

\section{Tartışma ve Sonuç}

Araştırmamızda destek personelin sosyodemografik özelliklerine göre iletişim becerileri ve empati eğilim düzeyleri incelendiğinde; saadece cinsiyete ile iletişim becerileri ve empati eğilim arasında anlamlı bir ilişki bulumuştur. Kadınların erkeklere göre daha yüksek iletişim becerileri (zihinsel ve davranışsal) ve empati eğilim düzeyine sahip olduğu belirlenmiştir. Benzer şekilde Harlak ve arkadaşlarının tıp fakültesi öğrencileri ile yaptıkları çalışmada da kadınların iletişim becerileri ve empati eğilimlerinin erkelere göre daha yüksek olduğu belirlenmiştir (Harlak vd., 2008, s.62; Unit vd., 2006, s.224; Hojat vd., 2002, s.526). Ayrıca toplam hizmet süresi ile duygusal, davranışsal ve genel iletişim beceri düzeyleri arasında ise istatistiksel açıdan anlamlı ilişki olduğu bulunmuştur. Bununla birlikte 20 yıldan daha az hizmet süresi olan HIV (+) hastalarla çalışan sağlık çalışanlarında empati eğilim düzeylerinin daha yüksek olduğu belirlenmiştir (Lin vd., 2012, s.1). Bununla birlikte bu çalışmada empati eğilim ile toplam hizmet süresi arasında anlamlı bir ilişki bulunamamıştır. Sağlık çalışanların empati düzeyinin yüksek olması hem kendileri hem de hastalar için önemlidir. Yapılan çalışmalar bunun geliştirilebilir olduğunu 
göstermektedir (Kelm vd., 2014, s.6-7; Özakgül vd., 2014, s.929; Moore vd., 2018).

Çalışmada hem iletişim becerileri hem de empati eğilim ile yaş, medeni durum, öğrenim ve gelir düzeyi arasında anlamlı bir ilişki bulunamamıştır. Bizim çalışmamızdan farklı olarak Çin'de yapılan bir çalışmada ise 31-40 yaş arasındaki sağlık çalışanlarında empati eğilim düzeylerinin daha yüksek olduğu ve öğrenim düzeyi azaldıkça empati eğilimin azaldığı belirlenmiştir. (Lin vd., 2012, s.1).

Kamu hastanelerinde yapılan bu çalışmada destek personelin çalıştıkları hastanede \%72.1'isinin iletişim ile ilgili hizmet içi eğitim aldıkları, \% 41.6'sı, aldıkları eğitimin iyi seviyede etkili olduğunu bildirmişlerdir. Katılımclların büyük çoğunluğu (\% 92) kendilerinin iletişim beceri düzeylerinin yüksek olduğunu düşünmektedirler. Ancak analiz sonuçlarına göre destek personelin iletişim becerileri ile empati eğilim düzeyleri ölçek puan ortalamalarının dağılımı incelendiğinde; iletişim beceri ve empati eğilim düzeylerinin orta düzeyde olduğu belirlenmiştir. Bizim çalımamızdan farklı olarak Lin vd tarafından hekim ve hemşire dışındaki sağlık çalışanlarının empati eğilimlerinin daha düşük olduğu gözlenmiştir (Lin vd., 2012, s.1).

Destek personelin iletişim ve empati eğilim düzeylerinin yeterli olmaması hem kendi sağlıkları hem de hizmet sundukları hastalar açısından olumsuz bir durumdur. Sağlık çalışanlarının empati düzeyi azaldığında hastalarla iletişimin azaldığı, ikincil travmatik stres ve tükenmişlik yaşama riskinin artığı belirlenmiştir (Passalacqua ve Segrin, 2012, s.454; Barrett, 2016, s.45-48; Wilkinson vd., 2017, s.18). Bununla birlikte etkili iletişim becerilerine sahip sağlik personelinden hizmet alan hasta ve hasta yakınlarının, aldıkları sağlık hizmetinden memnuniyet düzeylerinin arttığı, duygusal açıdan kendilerini daha rahat hissettikleri ve daha az depresif oldukları belirtilmektedir (Arifoğlu ve Sala Razı, 2011, s.7; Nørgaard vd., 2012, s.703; Fujimori, vd., 2014, s.2171). Ayrıca iletişim becerileri ilkelerine dayalı ekip çalışması eğitiminin ise ekip üyeleri arasında işbirliğini ve iletişimi geliştirdiğini bildirmiştir (McCulloch vd., 2010, s.477).

$\mathrm{Bu}$ çalışmada destek personelin iletişim becerileri ile empati eğilim ölçek puan ortalamaları karşılaştırıldığında, iletişim becerileri ve alt 
boyutları ile empati eğilim arasında pozitif yönde istatistiksel olarak anlamlı bir ilişki olduğu belirlenmiştir. Benzer şekilde Moore ve arkadaşları tarafından yapılan çalışmada de iletişim becerileri geliştirildiğinde empati eğilimin de arttığı gözlenmiştir (Moore vd., 2018).

Sonuç olarak, destek personelin iletişim beceri ve empati eğilim düzeylerinin orta düzeyde olduğu, iletişim becerileri ve alt boyutları ile empati eğilim arasında pozitif yönde istatistiksel olarak anlamlı bir ilişki olduğu belirlenmiştir. Kadınların erkeklere göre daha yüksek iletişim becerileri (zihinsel ve davranışsal) ve empati eğilim düzeyine sahip olduğu, toplam hizmet süresi ile de iletişim beceri (duygusal, davranışsal ve genel) düzeyleri arasında anlamlı ilişki olduğu bulunmuştur. Etkili sağlık hizmeti sunumunda dolaylı olarak hasta ve hasta yakınları ile sürekli iletişim içerisinde bulunan ve hizmet sunumunda aktif rol oynayan destek personellerinin iletişim becerileri ve empati düzeylerinin arttırılması gerektiği düşünülmektedir. Destek personeli de dahil tüm sağlık çalışanlarına, iletişim ve empati düzeylerinin arttırılmasına yönelik, etkili hizmet içi eğitimlerin düzenli aralıklarla ve etkili bir şekilde verilmesi, çalışanlardan sürekli geri bildirimler alınması önerilmektedir. Ayrıca destek personeli seçiminde kadın işgücüne öncelik verilebileceği düşünülmektedir. 
EXTENDED ABSTRACT

\section{Determination of Communication Skills and Empathy Levels of Support Staff: An Application in The Public Hospitals \\ Şirin Özkan - Gökhan Aba -Yusuf Çelik \\ Bandırma 17 Eylül University, Hacettepe University}

The effective delivery of health services is associated with the communication skills of healthcare team members. In health care system, all employees should have good communication skills because they have face to face communication with healthy people and patients. General definition of communication is two-way process of information exchange to reach mutual understanding clearly. Empathy is defined the ability to understand and share the feelings and experiences of someone and imagining what it would be like to be in that person's situation. It was determined that, health care workers's empathy towards patients were associated with providing high quality care, participation of the patient in treatment, higher patient satisfaction and commitment and better health outcomes. Employees taking part in all stages of health services are expected to provide effective care for the patients, provide support to the patients' relatives and maintain their own mental health. therefore, it is necessary to evaluate communication and empathy skills of all employees in health services and these skills should be supported to be improved by repetitive trainings. When patients come to hospitals, at first they meet with support staff before health professionals. Also patients are in direct communication with support staff as much as health professionals during their stay in hospital. The studies in the literature are generally conducted in health care workers. As far as we know, there was no study investigating the relationship between communication skills and empathic tendency levels of support staff. The aim of this study is to determine levels and relationship between communication skills and empathy tendency of support staff (receptionist, clinical assistants, patient services assistants and porters) in public hospitals. A descriptive study was conducted between January and June 2015 in all public hospitals (nine hospitals) in Kocaeli. The 
research population consisted of 867 support staff working in these hospitals. All the support staff working in hospitals were asked to include in the study and 426 support staff agreed to participate in the study. Sample of the study includes 387 support staff. Data was conducted as online survey. The questionnaire included questions about sociodemographic characteristics of the participants and communication skills and empathy scale. Communication Skills Scale was developed by Ersanlı and Balcı. The Empathic Tendency Scale was developed by Dökmen (1988), which aims to measure the empathy tendency of individuals in their daily life. According to our findings, 72,1\% of the support staff stated that they received in-service training about communication in the public hospitals, and $41,6 \%$ of them reported that the training they received was effective. The majority of respondents (92\%) think that their communication skill levels were high. However, according to the result of the analysis, level of communication skills and empathy of the support staff were found to be moderate. The weak communication and empathy levels of support staff is a negative condition both for their own health and patients. According to the results of Barrett's study, it was determined that hospital personnel who are not in direct relationship with the patient have higher levels of anxiety and discomfort caused by observing the negative experiences of patients. Subsequently, a higher level of empathic anxiety may increase its vulnerability to secondary traumatic stress.

According to the participants sociodemographic characteristics; it was found that women had higher communication skills (mental, behavioral, in total) and empathy tendency than men. Also there was a significant relationship between total service duration and emotional, behavioral and general communication skills $(\mathrm{p}<0,05)$. In addition, it was determined that there was a significant relationship between communication skills and sub-dimensions and empathy tendency. Additionally, other studies found that empathy tendency increases when communication skills develop. Also empathy of health workers decreases in parallel with patient-oriented communication and increase risk of burnout. As a result, good communication and empathy with the patients and their relatives has great importance in increasing the quality of the health service provided by all health workers. At this stage, not only health professionals but also support staff who have direct and indirect relationship with patients and their 
relatives have an active role in improving quality of the health service. In this context, communication skills and empathy levels of support staff should be increased. In conclusion, we recommend that to evaluate communication skills and empathy of support staff regularly and to organize effective in-service trainings in order to increase communication and empathy levels of support staff with all health workers.

\section{Kaynakça / References}

Akgün, R. ve Çetin, H. (2018). Üniversite öğrencilerinin iletişim becerilerinin ve empati düzeylerinin belirlenmesi. MANAS Sosyal Araştırmalar Dergisi, 7(3), 103-117.

Arifoğlu, B. ve Sala-Razı, G. (2011). Birinci sınıf hemşirelik öğrencilerinin empati ve iletişim becerileriyle iletişim yönetimi dersi akademik başarı puanı arasındaki ilişki. Dokuz Eylül Üniversitesi Hemşirelik Yüksekokulu Elektronik Dergisi, 4(1), 7-11.

Bahar, E. (2016). İletişim. Ankara:Detay Yayıncllık.

Barrett, M. G. (2016). The relationship between empathy and humor styles and secondary traumatic stress in the public mental health workplace. Doctoral dissertation, Antioch University Santa Barbara, CA.

Bauchat, J. R., Seropian, M. ve Jeffries, P. R. (2016). Communication and empathy in the patient-centered care model-why simulation-based training is not optional. Clinical Simulation in Nursing, 12 (8), 356-359.

Bekcan, S. (2015). İletişim becerileri, motivasyon ve sağlık çalışanları. Yayınlanmamış doktora tezi. Beykent Üniversitesi, Sosyal Bilimler Enstitüsü, İstanbul.

Dökmen, Ü. (1988). Empatinin yeni bir modele dayanılarak ölçülmesi ve psikodrama ile geliştirilmesi. Ankara Üniversitesi Eğitim Bilimleri Fakültesi Dergisi, 2(1-2), 155-190.

Ersanlı, K. ve Balcı, S. (1998). İletişim becerileri envanterinin geliştirilmesi: geçerlik ve güvenirlik çalışması. Türk Psikolojik Danışma ve Rehberlik Dergisi, 2 (10), 7-12.

Fujimori, M., Shirai, Y., Asai, M., Kubota, K., Katsumata, N. ve Uchitomi, Y. (2014). Effect of communication skills training program for oncologists based on patient preferences for communication when receiving bad news: a randomized controlled trial. Journal of Clinical Oncology, 32(20), 2166-2172. 
Harlak, H., Gemalmaz, A., Gurel, F. S., Dereboy, C. ve Ertekin, K. (2008). Communication skills training: Effects on attitudes toward communication skills and empathic tendency. Education for Health, 21(2), 1-6.

Hojat, M., Gonnella, J. S., Mangione, S., Nasca, T. J., Veloski, J. J., Erdmann, J. B., ... , Magee, M. (2002). Empathy in medical students as related to academic performance, clinical competence and gender. Medical education, 36(6), 522-527.

Kelm, Z., Womer, J., Walter, J. K., Feudtner, C. (2014). Interventions to cultivate physician empathy: a systematic review. BMC Medical Education, 14 (219), 1-11.

Lamothe, M., Rondeau, É., Malboeuf-Hurtubise, C., Duval, M. ve Sultan, S. (2016). Outcomes of MBSR or MBSR-based interventions in health care providers: a systematic review with a focus on empathy and emotional competencies. Complementary Therapies in Medicine, 24, 1928.

Lin, C., Li, L., Wan, D., Wu, Z. ve Yan, Z. (2012). Empathy and avoidance in treating patients living with HIV/AIDS (PLWHA) among service providers in China. AIDS Care, 24(11), 1341-1348.

McCulloch, P., Rathbone, J. ve Catchpole, K. (2011). Interventions to improve teamwork and communications among healthcare staff. British Journal of Surgery, 98(4), 469-479.

Moore, P. M., Rivera, S., Bravo-Soto, G. A., Olivares, C. ve Lawrie, T. A. (2018). Communication skills training for healthcare professionals working with people who have cancer. Cochrane Database of Systematic Reviews, 28(3), Art. No.: CD003751. DOI:10.1002/14651858.CD003751.pub3

Nørgaard, B., Kofoed, P. E., Ohm Kyvik, K. ve Ammentorp, J. (2012). Communication skills training for health care professionals improves the adult orthopaedic patient's experience of quality of care. Scandinavian Journal of Caring Sciences, 26(4), 698-704.

Okay, A. (2016). Sağllk iletişimi. İstanbul:Derin Yayınları.

Özakgül, A. A., Şendir, M., Atav, A. S. ve Kızıltan, B. (2014). Attitudes towards hiv/aids patients and empathic tendencies: a study of Turkish undergraduate nursing students. Nurse Education Today, 34(6), 929-933.

Özdemir, G. (2011). Ebelik ve hemşirelik öğrencilerinin iletişim becerileri ve yaşam yönelimlerinin stresle başetme tutumlar üzerine etkisi. Yayınlanmamış yüksek lisans tezi, İstanbul Üniversitesi, Sağlık Bilimleri Enstitüsü, İstanbul. 
Passalacqua, S. A. ve Segrin, C. (2012). The effect of resident physician stress, burnout, and empathy on patient-centered communication during the long-call shift. Health Communication, 27(5), 449-456.

Pazar, B., Demiralp, M., Erer, İ. (2017). The Communication skills and the empathic tendency levels of nursing students: A cross-sectional study. Contemporary Nurse, 53(3), 368-377.

Şahin, Z. A., Kardaş Özdemir, F. (2015). Hemşirelerin iletişim ve empati beceri düzeylerinin belirlenmesi. JAREN, 1(1), 1-7.

Tiryaki Şen, H., Taşkın Yılmaz, F. ve Pekşen-Ünüvar, Ö. (2013). Hizmet içi eğitim hemşirelerinin iletişim beceri düzeyleri. Journal of Psychiatric Nursing, 4(1), 13-20.

Unit, R. H. (2006). Empathy in health care providers-validation study of the Polish version of the Jefferson Scale of Empathy. Advances in medical sciences, 51, 219-225.

Wilkinson, H., Whittington, R., Perry, L. ve Eames, C. (2017). Examining the relationship between burnout and empathy in healthcare professionals: A Systematic Review. Burnout Research, 6, 18-29.

Toksöz, M. R. (1999). Yeni bir medya türü olarak etkileşimli bilgisayar oyunları. Yayımlanmamış Yüksek Lisans Tezi. Ankara Üniversitesi,Ankara, Türkiye.

Toran, M., Ulusoy, Z., Aydın, B., Deveci, T. ve Akbulut, A. (2016).Çocukların dijital oyun kullanımına ilişkin annelerin görüşlerinin değerlendirilmesi. Kastamonu Ĕ̆itim Dergisi, 24(5), 2263-2278.

Torun, F., Akçay, A. ve Çoklar, A. N. (2015). Bilgisayar oyunlarının ortaokul öğrencilerinin akademik davranış ve sosyal yaşam üzerine etkilerinin incelenmesi, Karaelmas Journal of Educational Sciences, 3, 25-35

Törüner, K. E. ve Büyükgönenç, L. (2012) Çocuk sağhlğı temel hemşirelik yaklaşımları. Ankara:Göktuğ Yayıncılık.

Yavuzer, Y. (2011). Okullarda saldırganlık/şiddet: Okul ve öğretmenle ilgili risk faktörleri ve önleme stratejileri. Millî Ĕ̆itim, 192, 43-61.

Y1lmaz, S. (2013). Spor yapan ve yapmayan ortaöğretim öğrencilerinin empatik eğ $i$ limleri ile saldırganlık düzeyleri arasındaki ilişkinin incelenmesi. Yayınlanmamış Yüksek Lisans Tezi. Yeditepe Üniversitesi, İstanbul, Türkiye. 


\section{Kaynakça Bilgisi / Citation Information}

Özkan, Ş., Aba, G. ve Çelik, Y. (2019). Destek personellerinin iletişim becerileri ve empati düzeylerinin belirlenmesi: Kamu hastanelerinde bir uygulama. OPUS-Uluslararası Toplum Araştırmaları Dergisi , 13(19), 1430-1446. DOI: 10.26466-/opus.561414 